\title{
Evaluation of dietary intake in a Danish population: the Inter99 study
}

\author{
Cathrine Lau ${ }^{1,2 *}$, Kristine Færch ${ }^{1,2 *}$, Charlotte Glümer ${ }^{1,3}$, \\ Ulla Toft ${ }^{3}$, Inge Tetens' ${ }^{2}$ Knut Borch-Johnsen' and \\ Torben Jørgensen ${ }^{3}$
}

'Steno Diabetes Centre, Gentofte, Denmark; ${ }^{2}$ Department of Human Nutrition, The Royal Veterinary and Agricultural University, Frederiksberg, Denmark and ${ }^{3}$ Research Centre for Prevention and Health, Glostrup, Denmark

\section{Abstract}

Background: During the past few decades there has been a worldwide increase in the prevalence of obesity and type 2 diabetes, and this may partly be due to an unfavourable dietary composition.

Objective: To evaluate the dietary intake of Danish men and women against the dietary recommendations, and to assess the daily glycaemic index $(d \mathrm{GI})$ and the daily glycaemic load $(d \mathrm{GL})$ of the diet.

Design: Baseline data from the Danish population-based Inter99 study were used. Dietary intake of 6635 men and women between 30 and 60 years of age was assessed through a food frequency questionnaire. The dietary intake was evaluated against the Nordic Nutrient Recommendations and the Danish food-based guidelines. Estimation of $d \mathrm{GI}$ and $d \mathrm{GL}$ was based on existing food tables.

Results: Men in the Inter99 study had higher intakes of all fat types, protein, carbohydrate, dietary fibre, alcohol and fish $\left(\mathrm{g} \mathrm{day}^{-1}\right)$ compared with women, whereas women had higher intakes of fruit and vegetables $\left(\mathrm{g}\right.$ day $^{-1}$ ) compared with men. The $d$ GI did not differ substantially between the genders, but men had a higher $d \mathrm{GL}$ than women. The recommendations for total, saturated, monounsaturated and polyunsaturated fat, carbohydrates, dietary fibre, fish, fruit and vegetables was met by less than $50 \%$ of the Inter99 population. Conclusions: The dietary composition in the Danish middle-aged population is not satisfactory compared with the recommendations, which may have detrimental consequences for health. The values of $d \mathrm{GI}$ and $d \mathrm{GL}$ were reasonable, but higher than estimates found in other studies.

Keywords: dietary assessment; dietary recommendations; food frequency questionnaire; glycaemic index; glycaemic load

Received: 27 May 2004; Revised: 23 July 2004; Accepted: 27 July 2004

\section{Introduction}

During the past few decades an increase in the prevalence of overweight, obesity and type 2 diabetes has been reported worldwide (1-4), and it is assumed that the prevalence of these conditions will increase in the future (5). Lifestyle factors such as diet and physical inactivity play a major role in the development of these metabolic complications $(6,7)$.

In 1996 the Nordic Council and Nordic Council of Ministers published the Nordic Nutrient Recommendations, with the aim of providing nutrientrelated guidelines for a diet, which considers the physiological needs of the individual and thereby

\footnotetext{
${ }^{*}$ C. Lau and K. Færch contributed equally to this study.
}

reduces the risk of diet-related illnesses. In addition, in Denmark the Danish Ministry of Food, Agriculture and Fisheries has formulated food-based dietary guidelines regarding the intake of alcoholic beverages, fish, fruit and vegetables, which are mainly regarded as a simple message to the population (8). There are no recommendations with regard to glycaemic index (GI) and glycaemic load (GL), but some observational studies suggest that diets with high GI and GL are independently associated with increased risk of type 2 diabetes and cardiovascular diseases $(7,9)$. Other epidemiological studies have found associations, in particular, between the intake of total and saturated fat and obesity, type 2 diabetes and cardiovascular diseases $(7,10)$. Dietary composition in a population may 
therefore affect the progression of disease to a certain degree.

The aim of this study was to evaluate the dietary intake of Danish men and women against the Nordic Nutrient Recommendations 1996 and the Danish food-based guidelines regarding intake of macronutrients, fruit and vegetables, fish and alcoholic beverages. A specific objective was to assess the daily glycaemic index and the daily glycaemic load in the diet of this population.

\section{Study design and methods}

\section{Study population and design}

The Inter99 study is a population-based nonpharmacological intervention study aimed at reducing the risk of cardiovascular disease and type 2 diabetes. The study population comprised 61301 individuals born in 1939-1940, 1944-1945, 19491950, 1954-1955, 1959-1960, 1964-1965, and 1969-1970 living in 11 municipalities in the southwestern part of Copenhagen County. All individuals were drawn from the Civil Registration System. An age- and gender-stratified random sample of 12934 eligible people was drawn from the study population. A total of 6906 participated in the screening programme. The participation rate was highest in the age groups of 40-55-year-olds $(53.2-54.2 \%)$ and lowest in the 30-year-olds (33.8\%). Of the 6906 participants, 122 were excluded because of alcoholism, drug abuse or linguistic barriers and 149 participants did not fill in the food frequency questionnaire (FFQ), leaving 6635 individuals for the dietary analyses. The aim, data collection and non-dietary baseline results of the cohort study have been reported elsewhere (11).

\section{Data collection}

All participants underwent a physical health examination and filled in a self-administered FFQ and a standard questionnaire on health and lifestyle.

The FFQ was based on validated FFQs used in the two Danish studies. "Diet, Cancer and Health" (12) and "Better Health for Mother and Child" (13). The FFQ in the Inter99 study was modified to improve estimates of the intake of fatty acids, cholesterol and complex carbohydrates, but had fewer questions regarding fruit and vegetables. The habitual food and nutrient intake during 1 month before examination was estimated. All participants completed the FFQ from March 1999 to January 2001.

The FFQ consisted of 198 food items and beverages; it included questions about breakfast foods; bread with sliced meat, fish, eggs, cheese, spread and vegetables; hot meals and accompaniments to hot meals; ready-prepared dishes and takeaway food; vegetables; salad dressing; sauce; fruits; snacks; cookies; candy and ice-cream; and beverages, including alcohol, but intake of soft drinks was not recorded. It also included questions about the type of fat used for food preparation and at the table. The participants could choose between seven and 11 possible responses, ranging from never to eight or more times per day.

The consumed quantity was obtained by multiplying portion size by the corresponding consumption frequency reported. Standard portion sizes for women and men, separately, were used in this calculation $(14,15)$. All food items in the FFQ were linked to food items in the Danish Food Composition Databank (16). For mixed meals standard recipes based on food items in the databank were developed at the Research Centre for Prevention and Health. In total, 244 food items were used, and these were divided into different food groups.

The GI for carbohydrate-containing food items was estimated using average GI values in the GI table by Foster-Powell et al. (17) with bread as reference food $(\mathrm{GI}=100)$. For food items in the table of Foster-Powell et al. where different preparation methods had yielded different GI values (often with very wide ranges), the values were chosen dependent on the preparation methods described in the recipes. The daily average glycaemic index $(d \mathrm{GI})$ for an individual was calculated by summing the products of the absolute available carbohydrate content in each food item eaten per day and the GI for each food item, divided by the total amount of available carbohydrate eaten $(18,19)$. The daily average glycaemic load $(d \mathrm{GL})$ was the sum of the products of the available carbohydrate content in each eaten food item and the GI for each food item, divided by 100 (20). The calculation of $d \mathrm{GI}$ and $d \mathrm{GL}$ was based on 57 different GI values ranging from 16 to 147 .

Estimation of amounts, energy percentages $(E \%)$ and energy intake for each subject in the Inter99 study was based on calculations in the software program FoodCalc version 1.3 (21). 
Weight was measured to nearest $0.1 \mathrm{~kg}$ using either an electronic or a mechanical standard weight (Seca 707, Seca 710) with the participant wearing light indoor clothes without shoes. Height was measured to the nearest $0.5 \mathrm{~cm}$ with the participant wearing no shoes. Body mass index (BMI) was calculated as weight in kilograms divided by the height in metres squared, and basal metabolic rate (BMR) was estimated by use of Schofield's equation (22). Waist measurement was taken with a tape measure halfway between the lowest point of the costal margin and highest point of the iliac crest.

To assess misreporting of energy intake, Goldberg's equation was used (23). For each individual the reported energy intake (EI) was divided by the estimated BMR (BMR est $)$. To avoid systematic underestimation of the energy intake used in the calculation of EI/BMR est $_{\text {an }}$ average intake of soft drinks equal to $302 \mathrm{~kJ}$ day $^{-1}(\sim 178 \mathrm{ml})$ for each participant was added to the total energy intake because of the missing questions about soft drinks in the FFQ. This average intake was based on 7 days' self-administered dietary records from the National Dietary Survey of Denmark 2001 for 952 men and women at 30-60 years of age (Fagt S, personal communication, 2003). Additional energy intake from soft drinks from the National Dietary Survey of Denmark 2001 was only used in the

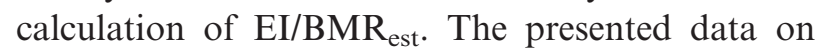
energy intake and macronutrients are therefore only based on the reported intakes from the Inter99 study.

\section{Evaluation of the diet}

Intake of macronutrients in energy percentages was evaluated against the Nordic Nutrient Recommendations (24), while intake of fish, alcoholic beverages, fruit and vegetables was evaluated against the Danish food-based guidelines $(8,25,26)$.

The estimated $d \mathrm{GI}$ and $d \mathrm{GL}$ in the Inter99 study were compared with the American Nurses' Health study and the Health Professionals' Follow-up study, in which a semiquantitative FFQ was used to assess the dietary intake (18-20).

The intake of macronutrients in the Inter99 population was compared with the National Dietary Survey of Denmark 1995 (NDSD 1995), which was a representative sample of the Danish population in 1995 (27). In NDSD 1995 dietary data were collected by use of a short personal interview supplemented by a 7 day self-administered dietary record with preprepared answering categories (27). Differences between Inter99 and the NDSD 1995 population were considered essential if the difference in median intake was more than $10 \%$. The age group in the NDSD was wider, ranging from 15 to 80 years, compared with 30 to 60 years in the Inter99 study, and therefore weighted means of macronutrient intake for an age-matched subsample (25-64 years) of NDSD 1995 were calculated. The dietary intakes in this subsample were not substantially different to the entire population of NDSD 1995, except for intake of alcohol, for which the intake was higher in the subsample compared with the entire population. However, since only limited data were available from this subsample comparison of dietary intake was made between the Inter99 population and the entire NDSD 1995 population.

\section{Statistical methods}

SAS 8.2 (SAS Institute, Cary, NC, USA) and R 1.8.1 (28) were used for data handling. Medians, percentiles, means and standard deviations were calculated. Since none of the dietary variables was normally distributed they were log-transformed, and the Student's $t$-test was used to test for significant differences between men and women. Trend tests were performed to test whether dietary intake differed across the age cohorts. A $p$-value of 0.05 was considered statistically significant.

\section{Results}

\section{The Inter 99 population}

Baseline characteristics of the Inter99 population are presented in Table 1. Table 2 shows the daily intake of energy in $\mathrm{MJ}$, macronutrients, fish, fruit and vegetables in grams together with the estimated $d \mathrm{GI}$ and $d \mathrm{GL}$. Even though $d \mathrm{GI}$ values were

Table I. Baseline characteristics for the Inter99 population $(n=6635)$

\begin{tabular}{lll}
\hline & Men & Women \\
\hline$n$ & $3223(48.6)$ & $3412(51.4)$ \\
Age (years) & $46.5 \pm 7.8$ & $45.8 \pm 7.9$ \\
BMI (kg m $\left.{ }^{-2}\right)$ & $26.8 \pm 4.0$ & $25.9 \pm 5.1$ \\
Waist circumference (cm) & $93.2 \pm 11.0$ & $80.4 \pm 12.3$ \\
BMR $_{\text {est }}(\mathrm{MJ})$ & $7.82 \pm 0.68$ & $6.05 \pm 0.53$ \\
\hline
\end{tabular}

Data for $n$ are absolute values with corresponding percentages in parentheses. Data for age, body mass index (BMI), waist circumference and estimated basal metabolic rate $\left(B M R_{\text {est }}\right)$ are given as means with corresponding standard deviations. 
Table 2. Daily intake of energy, macronutrients and selected food groups together with the estimated daily glycaemic index and daily glycaemic load for men and women in the Inter 99 population

\begin{tabular}{|c|c|c|c|}
\hline & $\begin{array}{l}\text { Men } \\
(n=3223)\end{array}$ & $\begin{array}{l}\text { Women } \\
(n=3412)\end{array}$ & $p$-value \\
\hline Energy (MJ) & II.I $(9.0,13.6)$ & $9.1(7.3,11.4)$ & $<0.001$ \\
\hline Fat $(g)$ & $98.2(74.3,133.3)$ & $74.3(55.6,103.0)$ & $<0.001$ \\
\hline Saturated fat (g) & $37.7(27.7,53.5)$ & $28.4(20.5,40.8)$ & $<0.001$ \\
\hline Monounsaturated fat $(\mathrm{g})$ & $32.9(24.6,45.5)$ & $24.1(17.7,34.1)$ & $<0.001$ \\
\hline Polyunsaturated fat (g) & $14.4(10.6,19.9)$ & II.I (8.1, 15.4) & $<0.001$ \\
\hline n-3 fatty acids (g) & $2.7(1.9,3.9)$ & $2.0(1.5,2.9)$ & $<0.001$ \\
\hline Carbohydrate (g) & $285.0(228.6,354.6)$ & $256.6(199.5,328.8)$ & $<0.001$ \\
\hline Added sugar (g) & $26.0(14.1,44.7)$ & $28.7(15.7,49.6)$ & $<0.001$ \\
\hline Dietary fibre $(\mathrm{g})$ & $25.0(18.9,32.2)$ & $23.0(17.3,29.7)$ & $<0.001$ \\
\hline Protein (g) & $94.3(77.8,113.2)$ & $78.1(63.2,95.3)$ & $<0.001$ \\
\hline Alcohol (g) & $13.2(5.0,29.6)$ & $6.1(1.9,13.5)$ & $<0.001$ \\
\hline Daily glycaemic index ${ }^{a}$ & $79(75,83)$ & $80(76,83)$ & $<0.001$ \\
\hline Daily glycaemic load ${ }^{\mathrm{a}}$ & $204(160,257)$ & $185(142,24 I)$ & $<0.001$ \\
\hline Fish and fish products $(\mathrm{g})$ & $25.1(13.6,46.0)$ & $20.3(9.9,33.6)$ & $<0.001$ \\
\hline Fruit and vegetables (g) & $182.0(102.5,318.2)$ & $301.6(167.6,504.9)$ & $<0.001$ \\
\hline
\end{tabular}

Data are medians with corresponding 25th and 75th percentiles in parentheses.

${ }^{a}$ Bread was used as reference (glycaemic index of bread $=100$ ) in the estimation.

almost equal for men and women, women had a significantly higher $d$ GI than men $(p<0.001)$. Men had a $10 \%$ higher $d$ GL than women $(p<0.001)$. Table 2 also shows that women had higher absolute intakes of added sugar, fruit and vegetables, whereas the men had higher absolute intakes of fish and all other macronutrients.

BMI and waist circumference, as well as the median intake in of alcohol, fish, fruit and vegetables $\left(\mathrm{g} \mathrm{day}^{-1}\right)$, increased across the age cohorts ( $p$-values for trend $<0.001)$. Conversely, median intakes of energy $\left(\mathrm{MJ}\right.$ day $\left.^{-1}\right)$, fat, carbohydrates and protein $\left(\mathrm{g}\right.$ day $\left.^{-1}\right)$, together with $d \mathrm{GI}$ and $d \mathrm{GL}$, decreased with increasing age ( $p$-values for trend $<0.001$ ).

Table 3 shows the intake of macronutrients expressed as energy percentages. Men had a rela-

Table 3. Intake of macronutrients in energy percentages for men and women in the Inter99 population

\begin{tabular}{lllr}
\hline & $\begin{array}{l}\text { Men } \\
(\boldsymbol{n}=\mathbf{3 2 2 3})\end{array}$ & $\begin{array}{l}\text { Women } \\
(\boldsymbol{n}=\mathbf{3 4 | 2 )})\end{array}$ & $\boldsymbol{p}$-value \\
\hline Fat $(E \%)$ & $34.6(29.5,41.2)$ & $32.1(26.6,38.6)$ & $<0.001$ \\
Carbohydrate $(E \%)$ & $44.2(38.3,49.5)$ & $48.3(42.6,54.6)$ & $<0.001$ \\
Protein $(E \%)$ & $14.5(12.8,16.3)$ & $14.6(12.8,16.5)$ & 0.236 \\
Alcohol $(E \%)$ & $3.6(1.4,7.5)$ & $2.0(0.7,4.4)$ & $<0.001$ \\
\hline
\end{tabular}

Data are medians with corresponding 25 th and 75 th percentiles in parentheses. tively high intake of fat and alcohol, whereas women had a relatively high intake of carbohydrate compared with men. The intake of protein in energy percentages did not differ between the genders.

The calculated mean EI/BMR $\mathrm{Bst}_{\text {es }}$ based on Goldberg's equation was $1.62(\mathrm{SD}=0.68)$.

\section{The Inter99 population versus the dietary recommendations}

Macronutrient intakes presented as energy percentages in the Inter99 population and NDSD 1995 and the corresponding recommendations are shown in Fig. 1. Twenty-seven per cent of the men and $40 \%$ of the women ( $34 \%$ of the whole population) had a total fat intake below $30 \mathrm{E} \%$, and the recommendation for saturated fat of maximum $10 E \%$ was only met by $16 \%$ men and $28 \%$ women $(22 \%$ of the whole population). Fifty-three per cent of the men and $42 \%$ of the women $(47 \%$ of the whole population) met the recommendations for monounsaturated fat, and the recommendation for polyunsaturated fat was met by $46 \%$ of the men and $39 \%$ of the women ( $43 \%$ of the whole population). For intake of $n-3$ fatty acids, more than $96 \%$ of both men and women had intakes corresponding to the recommendations of $>0.5 E \%$ (data not shown). The opposite tendency was observed with regard to carbohydrate

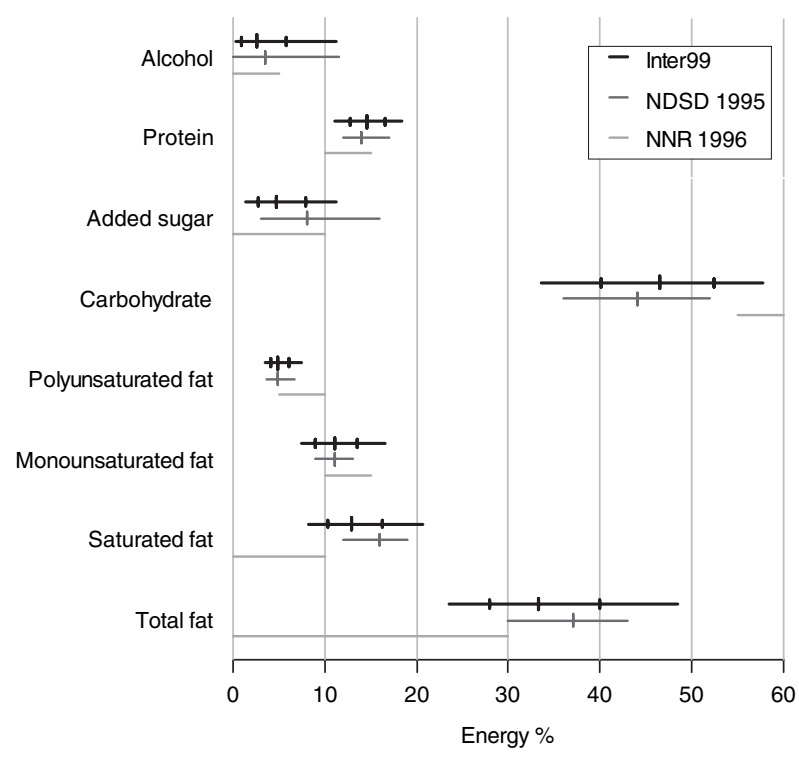

Fig. 1. Median dietary intake in the Inter99 population and in the National Dietary Survey of Denmark 1995 (NDSD 1995). The endpoints of each line are the 10th and 90th percentiles, the small vertical lines represent 25 th and 75 th percentiles, and the middle vertical line represents the median. The macronutrient recommendations are from the Nordic Nutrient Recommendation 1996 (NNR 1996). 
intake, where only $9 \%$ of the men and $24 \%$ of the women (16\% of the whole population) had intakes above $55 E \%$. This corresponded to a relatively low intake of fibre $\left(<25 \mathrm{~g} \mathrm{day}^{-1}\right)$ for $55 \%$ of the population (data not shown). A total of $86 \%$ of the study population met the recommendations for added sugar ( $92 \%$ of men and $82 \%$ of women). Ninety-three per cent had a protein intake above $10 \mathrm{E} \%$, and $50 \%$ of the population had a protein intake in the recommended range of $10-15 E \%$. With respect to intake of alcohol, $61 \%$ of the men and $79 \%$ of the women $(71 \%$ of the whole population) had an intake within the recommended $5 E \%$.

The median intake of fruit and vegetables in the Inter99 population was $230 \mathrm{~g} \mathrm{day}^{-1}$ (25th and 75 th percentiles: 128 and 431) compared with the foodbased guidelines of $600 \mathrm{~g} \mathrm{day}^{-1}(25)$. Only $6 \%$ of the men and $16 \%$ of the women $(11 \%$ of the population) had a fruit and vegetable intake equal to or above $600 \mathrm{~g}$ per day. With respect to fish products the median intake was $164 \mathrm{~g}$ week $^{-1}$ (25th and 75th percentiles: 77 and 289), and a total of $52 \%$ of the men and $63 \%$ of the women $(58 \%$ of the population) had an intake below the recommended intake of 200-300 g fish per week (8). The median intake of alcoholic beverages was 7.7 beverages per week for men (25th and 75th percentiles: 2.9 and 17.3) and 3.6 beverages per week for women (25th and 75th percentiles: 1.1 and 7.9). A total of $79 \%$ men and $88 \%$ women met the dietary guidelines of maximum 21 and 14 (26) alcoholic beverages per week, respectively.

\section{The Inter99 population versus the National Dietary Survey of Denmark}

Intake of monounsaturated fat, polyunsaturated fat, carbohydrate and protein differed by less than 10\% from the intake reported in the NDSD 1995. Furthermore, no difference in the median energy intake between Inter99 and NDSD 1995 was found (10.1 vs 9.9 $\mathrm{MJ} \mathrm{day}^{-1}$ ). The median intake of total fat, saturated fat, added sugar and alcohol was more than $10 \%$ lower in the Inter 99 study compared with the NDSD 1995 (Fig. 1) and the reported median intake of dietary fibre was $21 \%$ higher in the Inter99 study than in the NDSD 1995 (24 vs $19 \mathrm{~g}$ day $\left.^{-1}\right)$.

\section{Discussion}

The Inter99 study is the first epidemiological Danish study that has assessed $d$ GI and $d \mathrm{GL}$ in a relatively large population. The estimates of $d \mathrm{GI}$ and $d$ GL tended to be higher in the Inter99 study than in the Nurses' Health study and the Health Professionals' Follow-up study from USA. In the Nurses' Health study and the Health Professionals' Follow-up study the median $d$ GI were 71 and 73, respectively, and the median $d \mathrm{GL}$ were 144 and 160, respectively (18-20). The differences between $d$ GI and $d \mathrm{GL}$ in the Inter99 study and the American studies are likely to reflect true differences between the American and Danish diets and to reflect time changes, as data from the American studies were collected in the 1980s. A further explanation may be methodological differences between the studies in the estimation of GI for different food items. In addition, some of the difference in the estimated $d$ GL between the studies could be due to different degrees of carbohydrate underreporting in the studies. The estimates of $d$ GI for men and women in the Inter99 study suggest that no clinically relevant differences exist between the genders. The statistical difference in $d \mathrm{GI}$ for men and women was just a result of the large population size. Therefore, the higher $d \mathrm{GL}$ observed for men reflects a higher carbohydrate intake. There are no recommendations with regard to $d \mathrm{GI}$ and $d \mathrm{GL}$, but through more research and knowledge in this area, there may be a basis for recommendations considering these values.

Despite a reduction in the intake of dietary fat in the Danish population from 1995 to 1999 (27) the fat intake was still higher than recommended, and men in particular had a high intake of total fat and saturated fat compared with the recommendations. This gender difference is probably caused by men's higher intake of meat and fats (data not shown). The younger age groups, in particular, had high fat intakes, whereas those at 60 years of age met the recommendations to a higher degree. Meeting the recommendations for total and saturated fat is of major importance, since excess fat in the diet may lead to overconsumption of energy, followed by obesity, type 2 diabetes and cardiovascular disease $(7,10)$. The intake of polyunsaturated fat was only within the recommendations for a minority of the Inter99 population, while the intake of $n-3$ fatty acids was within the recommendations for most of the population. Intakes of these fatty acids are important concerning their possible protective effect in the prevention of type 2 diabetes and cardiovascular diseases $(7,10)$. The reported intake of dietary 
fibre was also below the recommendations for more than $50 \%$ of the population, but the reported intake of added sugar was within the recommended limit for the majority of the population. Meeting the recommendations for intake of dietary fibre may improve blood glucose regulation and glycaemic control, and lower $d \mathrm{GI}$ and $d \mathrm{GL}$, which in turn may lower the risk of developing insulin resistance, impaired glucose tolerance and type 2 diabetes (9).

In spite of an observed increase in the intake of fruit and vegetables over the past decade $(29,30)$, only $16 \%$ of the women and $6 \%$ of the men met the recommendations in the Inter99 study. The gender differences observed with respect to fruit intake may be explained by the fact that health campaigns have more of an effect on women than on men, and thus on average women eat a healthier diet with more fruit and vegetables (31). The fish intake was substantially lower than the recommended level for both men and women, especially in the younger age groups, despite the fact that the intake of n-3 fatty acids $(E \%)$ was met by most of the population. This reflects that there may not always be agreement between food-based guidelines and nutrient recommendations, and this may be caused by the fact that the intake of nutrients from a food group depends on both the amount of the food item consumed and the type and quality of the food. Disagreement between food-based guidelines and the nutrient recommendations was also observed for the alcohol recommendations, for which a higher proportion of the population met the recommendations for beverages per week compared with the recommendation in energy percentages.

In the Inter99 population a mean value for EI/ $\mathrm{BMR}_{\text {est }}$ of 1.62 was found. Goldberg et al. (23) suggest that an average EI/BMR ${ }_{\text {est }}$ of 1.54 can be used as the cut-off limit for underreporting in populations above 2000 individuals. By use of this empirical approach, the present finding thus indicates that underreporting was not a major problem in this study.

In the comparison between the Inter99 population and the population from NDSD 1995, differences were observed with respect to intake of total fat, saturated fat, alcohol, added sugar and dietary fibre. Differences in dietary intake between the studies may have numerous explanations, such as methodological differences in dietary assessment, changes in dietary patterns from 1995 to 1999 and differences in study populations.
The relatively low intake of added sugar in the Inter99 study compared with the NDSD 1995 is probably caused by the fact that soft drinks, juice, some sweet products and some of the relatively new products, such as low-fat, carbohydrate-rich products and cider, were not included in the Inter99 FFQ. The exclusion of alcoholics in the Inter99 study could partly explain the relatively low alcohol intake in the Inter99 study compared with the NDSD 1995. Moreover, it is assumed that alcohol consumption is underreported to a higher degree by use of dietary collection methods where long-term intake is reported (FFQ) compared with methods assessing the intake for only a few days (7 day food record). The higher intake of dietary fibre and lower intake of total and saturated fat in the Inter99 study may be due to differences in the choice of recipes used in the calculations of the diet, or to other methodological differences in the data collection method. The lower intake of fat in the Inter99 study may also reflect a time trend in the diet in the direction of greater availability and consumption of low-fat products (32). A time trend has also been observed for intake of fruit and vegetables from 1995 to $2001(27,29,30)$. The limited number of questions regarding fruit, vegetables and juice may explain why the reported intake of fruit and vegetables in the Inter99 population did not reflect this time trend.

The Inter99 study offers an intervention based on lifestyle modification with diet, physical activity and smoking cessation to individuals at high risk of developing cardiovascular disease or diabetes. Hence, it is possible that those who were obese and overweight or had an unhealthy lifestyle were more likely to participate in the intervention programme for lifestyle modification than those who considered themselves to have a relatively healthy lifestyle $(11,33)$. This was also reflected by the mean BMI, which was 9\% higher in the Inter99 population than in NDSD 1995 (34). However, BMI in NDSD 1995 was based on self-reported weight and height (34), and this would underestimate the true BMI. The representativeness of the Inter99 population has been studied by comparing morbidity in attenders versus non-attenders. This analysis revealed that attenders in the Inter99 study had lower morbidity based on hospitalizations than the whole invited population (33). This suggests that the Inter99 population is representative. However, owing to the higher response rate in 
the 40-55-year-olds and a higher number of individuals invited at the age of 40-55 years (11) the dietary data may reflect the dietary intake of this part of the population to a higher degree.

In conclusion, it seems reasonable to suggest that the dietary intake of the Inter99 population is representative of the diet in the middle-aged Danish population. Reported dietary intake for the majority of this population met the recommendations for protein and n-3 fatty acids, but it did not meet the recommendations for total, saturated, monounsaturated and polyunsaturated fat, carbohydrate, dietary fibre, fish, fruit and vegetables. Because of limitations in data collection it was not possible to conclude whether the population met the recommendations with respect to intake of added sugar and alcohol. The dietary composition in the Inter99 population was in general not satisfactory compared with the Nordic and Danish dietary recommendations. For those groups that in general do not meet the recommendations, a problem may exist in their ability to maintain good health and to minimize the risk of diet-related illnesses.

\section{Acknowledgements}

This study was supported by the Danish Medical Research Council, the Danish Centre for Evaluation and Health Technology Assessment, Novo Nordisk A/S, Copenhagen County, the Danish Heart Foundation, the Danish Diabetes Association, the Danish Pharmaceutical Association, the Augustinus Foundation, the Ib Henriksen Foundation and the Becket Foundation. The authors thank all the participants who took part in the survey. Staff from the Research Centre for Prevention and Health and the laboratory at Steno Diabetes Centre are thanked for their serious efforts that made this study possible. Special thanks to Henning Østerby and Bendix Carstensen for data handling support.

Steering committee of Inter99: Torben Jørgensen (principal investigator), Knut Borch-Johnsen (principal investigator, diabetes part), Troels Thomsen and Hans Ibsen.

\section{References}

1. Drivsholm T, Ibsen H, Schroll M, Davidsen M, BorchJohnsen K. Increasing prevalence of diabetes mellitus and impaired glucose tolerance among 60-year-old Danes. Diabet Med 2001; 18: 126-32.

2. Matthiesen J, Andersen NL, Ovesen LF. The role of diet and physical activity in the increasing prevalence of overweight and obesity in Denmark 1985-1995 (Betydningen af kost og fysisk aktivitet for fedmeudviklingen $\mathrm{i}$ Danmark fra 1985 til 1995). Ugeskr Laeger 2001; 21.
3. Raben A. Jumbosize Europe? European Union conference on obesity calls for immediate action. Scand J Nutr 2003; 47: 29-38.

4. Bendixen $H$. Changes in prevalence of overweight, obesity, and slimming behaviour in Danish adults with emphasis on dietary fat quality. Department of Human Nutrition, Royal Veterinary and Agricultural University, Frederiksberg, Denmark; 2003.

5. King H, Aubert RE, Herman WH. Global burden of diabetes, 1995-2025: prevalence, numerical estimates, and projections. Diabetes Care 1998; 21: 1414-31.

6. Astrup A. Healthy lifestyles in Europe: prevention of obesity and type II diabetes by diet and physical activity. Public Health Nutr 2001; 4(2B): 499-515.

7. Steyn NP, Mann J, Bennett PH, Temple N, Zimmet P, Tuomilehto J, et al. Diet, nutrition and the prevention of type 2 diabetes. Public Health Nutr 2004; 7(1A): 14765.

8. Haraldsdottir J. Dietary guidelines and patterns of intake in Denmark. Br J Nutr 1999; 81(Suppl 2): S43-8.

9. Brand-Miller JC. Glycemic load and chronic disease. Nutr Rev 2003; 61: S49-55.

10. Srinath Reddy KKM. Diet, nutrition and prevention of hypertension and cardiovascular diseases. Public Health Nutr 2004; 7(1A): 167-86.

11. Jørgensen $\mathrm{T}$, Borch-Johnsen $\mathrm{K}$, Thomsen TF, Ibsen H, Glumer C, Charlotta P. A randomized non-pharmacological intervention study for prevention of ischaemic heart disease: baseline results Inter99 (1). Eur J Cardiovasc Prevent Rehabil 2003; 10: 377-86.

12. Tjonneland A, Overvad K, Haraldsdottir J, Bang S, Ewertz M, Jensen OM. Validation of a semiquantitative food frequency questionnaire developed in Denmark. Int J Epidemiol 1991; 20: 906-12.

13. Friis S, Kruger KS, Stripp C, Overvad K. Reproducibility and relative validity of a self-administered semiquantitative food frequency questionnaire applied to younger women. J Clin Epidemiol 1997; 50: 303-11.

14. Haraldsdóttir J, Seppänen R, Steinrímsdóttir L, Trygg K, Hagman U. Portionsstorleker - Nordiska standardportioner av mat och livsmedel (Portion sizes - Nordic standard portions of food and foodstuffs). Nordic Council \& Council of Ministers, Sweden; 1998. p. 1-41.

15. Biltoft-Jensen A. Danskernes kostvaner 2000-2002. Teknisk rapport (The National Dietary Survey of Denmark 2000-2002. Technical Report) (unpublished work); 2004.

16. Møller A, Saxholt E, Christensen AT, Hartkopp HB. Fødevaredatabanken version 5.0 (Food databank version 5.0). Fødevareinformatik, Institut for Fødevaresikkerhed og Ernæring, Fødevaredirektoratet (Danish Ministry of Food, Agriculture and Fisheries), Denmark. Available from: URL: http://www.foodcomp.dk (1 Oct. 2002).

17. Foster-Powell K, Holt SHA, Brand-Miller JC. International table of glycemic index and glycemic load values: 2002. Am J Clin Nutr 2002; 76: 5-56.

18. Salmeron J, Ascherio A, Rimm EB, Colditz GA, Spiegelman D, Jenkins DJ, et al. Dietary fiber, glycemic 
load, and risk of NIDDM in men. Diabetes Care 1997; 20: $545-50$.

19. Salmeron J, Manson JE, Stampfer MJ, Colditz GA, Wing AL, Willett WC. Dietary fiber, glycemic load, and risk of non-insulin-dependent diabetes mellitus in women. JAMA 1997; 277: 472-7.

20. Liu S, Willett WC, Stampfer MJ, Hu FB, Franz M, Sampson L, et al. A prospective study of dietary glycemic load, carbohydrate intake, and risk of coronary heart disease in US women. Am J Clin Nutr 2000; 71: 1455-61.

21. Lauritsen J. FoodCalc. Available from: URL: http:// www.ibt.ku.dk/jesper/FoodCalc/Default.htm (12 Feb. 2004).

22. Food and Agriculture Organization of the United Nations/World Health Organization/United Nations University. Energy and protein requirements. Report of a Joint FAO/WHO/UNU Expert Consultation. World Health Organ Tech Rep Ser 1985; (724): 1-206.

23. Goldberg GR, Black AE, Jebb SA, Cole TJ, Murgatroyd PR, Coward WA, et al. Critical evaluation of energy intake data using fundamental principles of energy physiology: 1. Derivation of cut-off limits to identify under-recording. Eur J Clin Nutr 1991; 45: 569-81.

24. Sandström B, Aro A, Thórsdóttir I, Becker W, Lyhne N, Pedersen JI. Nordiska Näringsrekommendationer 1996 (Nordic nutrient recommendations 1996). 1st edn. Copenhagen: Nordic Council \& Council of Ministers; 1996.

25. Trolle E, Fagt S, Ovesen L. Fruit and vegetables. Recommended intakes. Danish Ministry of Food, Agriculture and Fisheries, Denmark; 1998. p. 1-221.

26. National Board of Health. Fakta om alkohol - Gode råd om at drikke mindre (Facts about alcohol - advice of lesser drinking). National Board of Health, Denmark; 2002. p. 1-23.

27. Andersen NL, Fagt S, Grith MV, Hartkopp HB, Møller A, Ovesen L, et al. Danskernes kostvaner 1995. Hovedresultater (National Dietary Survey of Denmark 1995.
Main results). Danish Ministry of Food, Agriculture and Fisheries, Denmark; 1996.

28. $\mathrm{R}$ version 1.8.1. Available from URL: http://www. r-project.org/ (15 Jan. 2004)

29. Haraldsdottir J, Astrup AV, Dynesen AW, Holm L. Danskernes foedevareforbrug i stadig aendring. Klare tendenser i perioden 1995-2001 (Steadily changing food consumption of Danes. Clear trends during the period 1995-2001). Ugeskr Laeger 2002; 164: 2028-33.

30. Fagt S, Matthiessen J, Trolle E, Lyhne N, Christensen T, Hinsch H, et al. Danskernes kostvaner 2000-2001 (National Dietary Survey of Denmark 2000-2001), 1st edn. Ministry of Food, Agriculture and Fisheries, Denmark; 2002.

31. Holm L, Dynesen AW, Astrup AV, Haraldsdottir J. De store ernæringskampagner virker faktisk! (The large campaign to improve food habits has indeed had its effect!). Ugeskr Laeger 2002; 164: 649-51.

32. Astrup A. The American paradox: the role of energydense fat-reduced food in the increasing prevalence of obesity. Curr Opin Clin Nutr Metab Care 1998; 1: 573 7.

33. Glümer C. Screening for type 2 diabetes - Dia-Risk. $\mathrm{PhD}$ Thesis. Faculty of Health Sciences, University of Copenhagen, Denmark; 2003.

34. Groth MV, Fagt S. National Dietary Survey of Denmark 1995. Technical Report 1. Danish Ministry of Food, Agriculture and Fisheries, Denmark; 1997.

\section{Cathrine Lau}

Cand Scient. Human Nutrition

Steno Diabetes Centre

Niels Steensensvej 2-4

DK-2820 Gentofte

Denmark

Tel: +454442 01 । I

Fax: +4544430706

E-mail: cala@steno.dk 